\title{
Malignant pleural mesothelioma metastatic to the submandibular salivary gland, simulating glandular hypertrophy, diagnosed by fine-needle aspiration biopsy: a case report and literature review
}

\author{
Massimo Ambroggi ${ }^{1}$, Elena Orlandi ${ }^{1}$, Raoul P Foroni ${ }^{2}$ and Luigi Cavanna ${ }^{1 *}$
}

\begin{abstract}
Background: Malignant mesothelioma is a rare neoplasm that generally develops in the pleural or peritoneal cavity. Distant metastases are common; it rarely metastatizes to the head and neck region.

Case presentation: A 54-year-old white man, a non-smoker, was treated with chemotherapy, surgery and radiation for a malignant pleural mesothelioma. Seven months after the last treatment, he developed a right submandibular enlargement: clinical examination, ultrasound and computerized tomography scans revealed a salivary gland hypertrophy. Anti-inflammatory and antibiotic treatment was then started, without improvement. An ultrasound (US)-guided fine-needle aspiration biopsy (FNAB) showed atypical mesothelial cells with nuclear enlargement and increased chromatin representation. Immunocytochemistry showed positivity for calretinin and WT-1.

A diagnosis of right submandibular salivary gland involvement from mesothelioma was established, allowing an adequate treatment.
\end{abstract}

Conclusion: We report a very rare site of metastasis from malignant pleural mesothelioma. We suggest that US-guided FNAB is a useful, quick, and cheap procedure for a definite diagnosis.

Keywords: Mesothelioma, Salivary gland metastasis, Fine needle aspiration

\section{Background}

Malignant mesothelioma is a rare neoplasm with an incidence rate of 1 per 100,000 (both sexes, United States) [1].

Approximately $80 \%$ of cases of mesothelioma develop in the pleural cavity, whereas the other $20 \%$ arise in the peritoneum; the pericardium is affected very rarely [2].

Metastases from malignant mesothelioma are common, usually to the local lymph nodes, pleurae of the contralateral lung, bone, liver and brain [3]. However, metastases to the head and neck region are uncommon but the jaw bones, particularly the mandibular molar

\footnotetext{
* Correspondence: I.cavanna@ausl.pc.it

'Department of Oncology and Hematology, Oncology Unit, Azienda Ospedaliera 'Guglielmo da Saliceto', Via Taverna 49, 29100 Piacenza, Italy Full list of author information is available at the end of the article
}

area, are more likely to be the site of metastases than the perioral region [4-19].

We present a 54-year-old man, a non-smoker, with no occupational exposure to asbestos with malignant pleural mesothelioma, previously treated with surgery, radiotherapy and chemotherapy. He presented with right submandibular salivary gland enlargement, diagnosed using US and computerized tomography (CT) scan imaging techniques, as salivary gland hypertrophy, while a fine-needle aspiration biopsy (FNAB) showed metastasis from malignant mesothelioma.

\section{Case presentation}

A 54-year-old Caucasian man underwent right pleural biopsy in December 2005 for recurrent pleural effusion and locally advanced malignant mesothelioma was

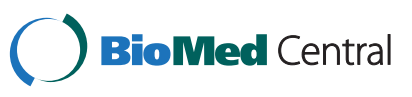

(c) 2014 Ambroggi et al.; licensee BioMed Central Ltd. This is an Open Access article distributed under the terms of the Creative Commons Attribution License (http://creativecommons.org/licenses/by/2.0), which permits unrestricted use, distribution, and reproduction in any medium, provided the original work is properly credited. 
diagnosed. Subsequently, he was treated with chemotherapy containing cisplatin and pemetrexed for seven cycles; CT scan showed a partial response. In December 2006, he underwent surgery involving total right pleuropneumonectomy plus partial resection of the pericardium and diaphragm. The histological features showed epithelioid malignant mesothelioma involving the parietal and the visceral pleurae, the lung, the pericardium and the diaphragm.

Subsequent radiotherapy to the right chest was administered using $50.4 \mathrm{~Gy}, 28$ fractions.

The patient remained disease-free until June 2009 when an isoechogenic and hypodense nodule of $35 \times$ $16 \mathrm{~mm}$ was discovered on US and CT scan in the right side of the anterior abdominal wall. An ultrasoundguided biopsy showed metastasis of mesothelioma. In August 2009, the nodule was surgically removed, and radiotherapy was then administered to this site using 45 Gy, 15 fractions.

In September 2011, a relapse in the mediastinum (lymph nodes) was found by CT scan and Positron Emission Tomography (PET), so six cycles of chemotherapy with cisplatin and pemetrexed were started which lasted until January 2012. Complete response at PET examination in February 2012 was demonstrated.

In November 2012, a right submandibular salivary gland tumefaction was recorded. US examination showed right submandibular gland hypertrophy (Figure 1), confirmed on CT scan and with neither US nor CT signs of metastasis; a diagnosis of inflammation of the gland was made. Anti-inflammatory therapy was administered; the patient also received antibiotic therapy but without improvement.
An US-guided FNAB of the right submandibular salivary gland was then performed using a 22-gauge needle and showed atypical mesothelial cells, with nuclear enlargement and increased chromatin representation (Figure 2). Immunocytochemistry showed positivity for calretinin (Figure 3) and nuclear, weak and focal positivity for WT-1 (Figure 4). Based on the previous history of malignant mesothelioma and the morphologic features of the cells, immunocytochemistry allowed confirmation of the diagnosis of right submandibular involvement from epithelioid mesothelioma. The subsequent PET scan was positive for the right submandibular salivary gland. The patient was treated with radiotherapy to this site.

\section{Literature review}

A computerized literature search through MEDLINE, Cancerlit and Embase was performed, in order to make a comparison with our case, applying the words: 'mesothelioma', 'metastasis', 'oral cavity', 'mouth', 'buccal', 'tongue', 'head and neck area'. Articles and abstracts were also identified by back-referencing from original and relevant papers. Selected for the present review were papers published in English before April 2013.

\section{Conclusion}

With this case report, we would like to focus on two aspects: 1) metastases from mesothelioma to the head and neck area (except for lymph nodes), in particular to the salivary glands, are very rare; 2) diagnosis of metastasis from mesothelioma is made usually by biopsy, and not by FNAB as in our case (Table 1 ).

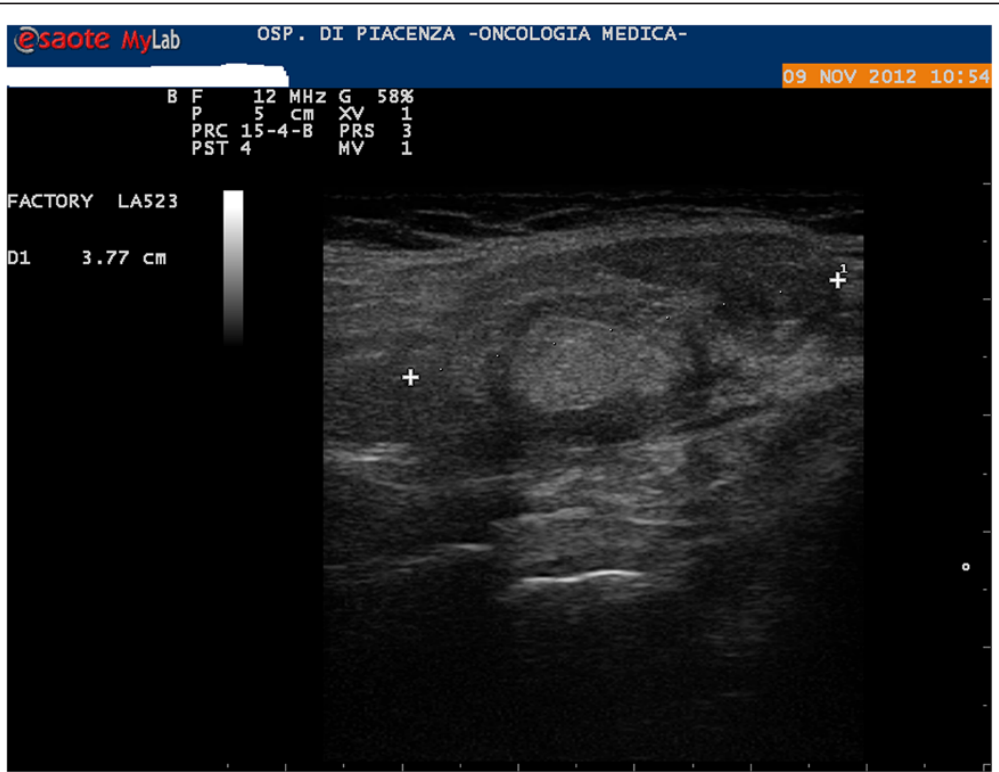

Figure 1 Ultrasound image showing a right submandibular salivary gland enlargement with a low-echogenic pattern. 


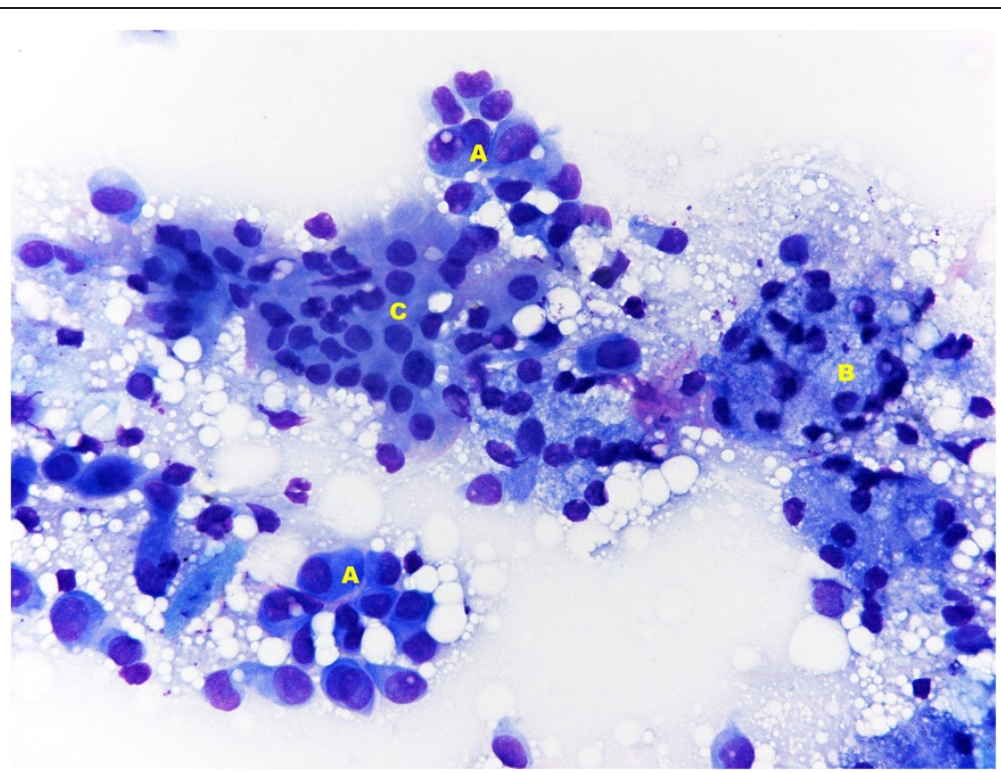

Figure 2 Fine-needle aspiration biopsy (FNAB) of right submandibular salivary gland shows atypical mesothelial cells with nuclear enlargement and increased chromatin representation (A) and normal salivary gland cells ((B) acinar cells; (C) ductal cells). May-GrünwaldGiemsa (MGG) x40.

Reviewing the literature, we found 17 other cases of metastases to the head and neck area (except for lymph nodes) from mesothelioma, but none to the salivary glands. The most involved site was the tongue, with different clinical presentations, followed by the mandible and in particular the mandibular alveolus, and then the oral mucosa. The clinical presentation can be of a benign polypoid-like lesion of the tongue or a radicular cyst in the mandibular alveolus, with only cyto-histological examination allowing a definite diagnosis.

The diagnosis of primary malignant mesothelioma is established by a combination of clinical, imaging, histopathological and immunohistochemical features. The diagnosis of a secondary mesothelioma is easier and can be made more rapidly since there is a previous diagnosis of the primary lesion [19]. However, even with the

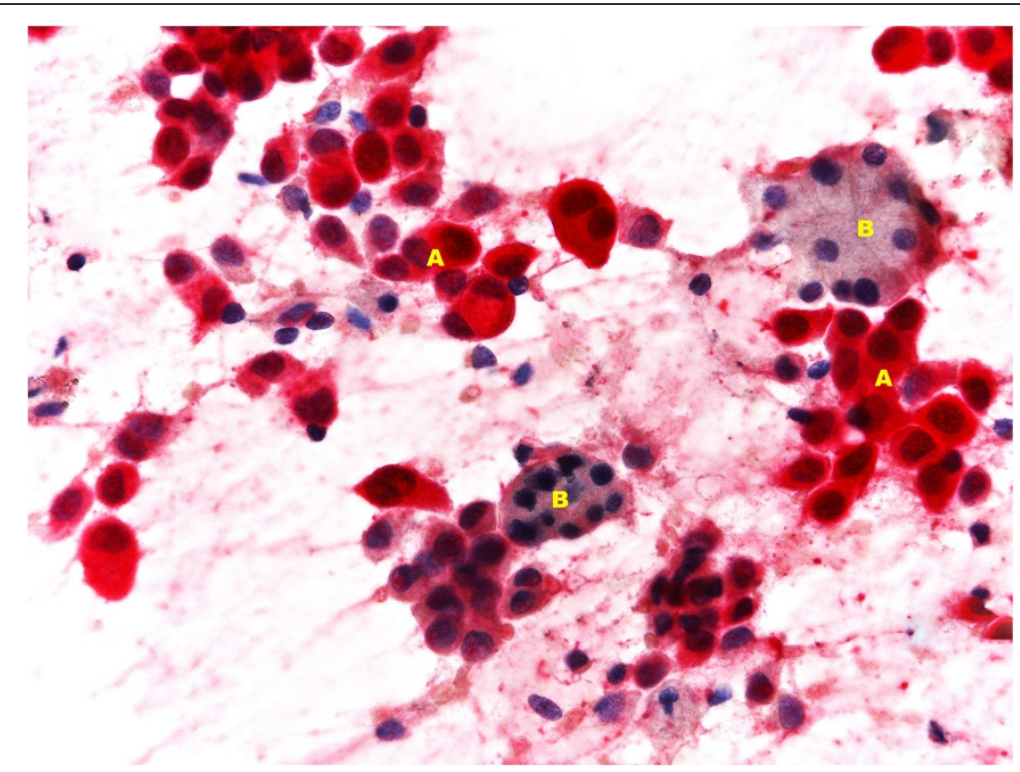

Figure 3 Fine-needle aspiration biopsy (FNAB) of right submandibular salivary gland shows neoplastic mesothelial cells positive for calretinin (A) and normal acinar glandular cells (B). Immunocytochemistry, Fast red N.4. 


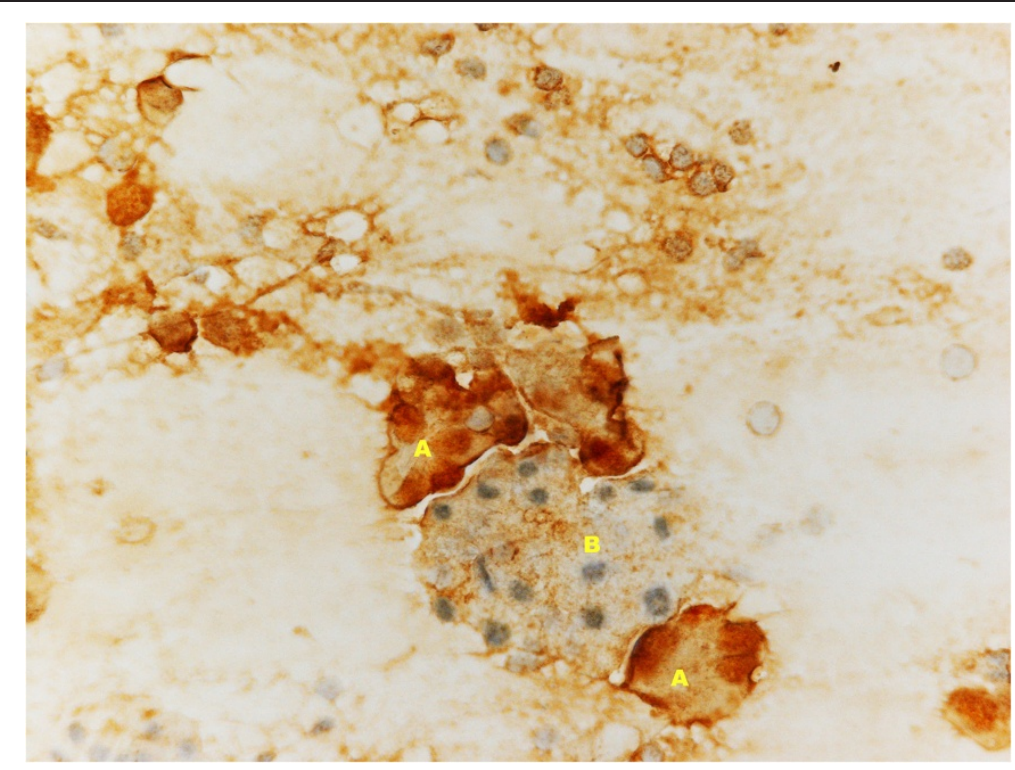

Figure 4 Fine-needle aspiration biopsy (FNAB) of right submandibular salivary gland, showing nuclear, weak and focal, immunocytochemically WT-1 positive mesothelioma cells (A) and normal acinar salivary gland cells (B). Immunocytochemistry, DAB.

knowledge of a primary mesothelioma it is necessary to perform a definite diagnosis of a putative lesion to allow appropriate management of the patient.

Reviewing the literature, in almost all cases of head and neck metastases from mesothelioma, incisional or excisional biopsy was performed to obtain the diagnosis; in some cases surgical excision was needed. We found no cases diagnosed by FNAB.

Fine-needle aspiration biopsy (FNAB) is a clinically accepted, minimally invasive technique that allows sampling of tumor for diagnosis by percutaneously directing a needle into the target lesion guided either by direct palpation or under image guidance [20]. In general, the accuracy, specificity and sensitivity of FNAB results depend on the size of the lesion, the method of biopsy, and the histology of the tumor [21]. When FNAB is applied as a diagnostic technique in patients with suspected malignant mesothelioma, the accuracy of diagnosis may be low.

Though the cytologic diagnostic features of malignant mesothelioma were described more than 50 years ago, there is still doubt as to the ability of the cytopathologic modality to obtain a definitive diagnosis of malignant mesothelioma [22-24].

The published sensitivity of cytologic diagnosis of mesothelioma ranges between $32 \%$ and $76 \%$, and this wide range of sensitivity is probably related to the sampling technique rather than the interpretation [24].

It must be emphasized that application of immunocytochemical and molecular techniques greatly enhance

Table 1 Review of head and neck (except for lymph node) metastases from mesothelioma published in the literature

\begin{tabular}{|c|c|c|c|c|}
\hline Site of metastasis & Number of patients & Clinical presentation & Diagnostic modality & References \\
\hline Tongue & 7 & $\begin{array}{l}\text { Tongue lesion, nodular consolidation of the tongue } \\
\text { with chronic bleeding, submucosal mass, horizontal } \\
\text { fissure, swelling of the dorsal surface of the tongue, } \\
\text { polypoid lesion }\end{array}$ & $\begin{array}{l}\text { Surgery, lingual incisional } \\
\text { and excisional biopsy }\end{array}$ & {$[5,7,10,14-16,18]$} \\
\hline Mandible & 4 & $\begin{array}{l}\text { Radicular cyst, mandibular gingival mass, } \\
\text { periapical radiolucency }\end{array}$ & $\begin{array}{l}\text { Excision of the tooth, } \\
\text { biopsy, incisional biopsy, } \\
\text { excision of the mass }\end{array}$ & {$[5,6,8,12]$} \\
\hline Oral mucosa & 3 & Submucosal mass & Biopsy & {$[11,17,19]$} \\
\hline Lips & 1 & Lip lesion & Lip biopsy & [9] \\
\hline Conjunctiva & 1 & $\mathrm{n} / \mathrm{a}$ & $\mathrm{n} / \mathrm{a}$ & [11] \\
\hline Thyroid & 1 & $\mathrm{n} / \mathrm{a}$ & $\mathrm{n} / \mathrm{a}$ & [11] \\
\hline Total & 17 & & & \\
\hline
\end{tabular}

We collected the previously published cases of metastases from mesothelioma to the head and neck area, except for lymph node metastases. Tongue was the most frequent site of metastases, with different clinical presentations; no metastases to the salivary glands had previously been found, and no diagnoses of metastases with FNAB had been made. 
the diagnostic accuracy of cytologic diagnosis of malignant mesothelioma [25-27]. FNAB biopsies are an ideal method for detecting tumor relapse during the life cycle of the cancer [28], as demonstrated in our case where the imaging techniques of US and CT scans suggested only salivary gland hypertrophy, while FNAB confirmed mesothelioma relapse.

This case is interesting in that it demonstrates a rare site of metastasis from malignant mesothelioma, and shows the efficacy of FNAB for a definite cytologic diagnosis, thus allowing optimum treatment.

\section{Consent}

Written informed consent was obtained from the patient for the publication of this report and any accompanying images.

\section{Abbreviations \\ FNAB: fine needle aspiration biopsy; US: ultrasound; CT: computerized tomography; PET: Positron Emission Tomography.}

\section{Competing interests}

The authors declare that they have no competing interests.

\section{Authors' contributions}

MA and EO took care of the clinical case presentation and revised the literature. $L C$ revised the literature and FNAB use, and wrote discussion and conclusion. RPF took care of the pathological aspects and provided cytological figures. All authors read and approved the final manuscript.

\section{Author details}

'Department of Oncology and Hematology, Oncology Unit, Azienda Ospedaliera 'Guglielmo da Saliceto', Via Taverna 49, 29100 Piacenza, Italy. 'Department of Pathology, Azienda Ospedaliera 'Guglielmo da Saliceto', Via Taverna 49, 29100 Piacenza, Italy.

Received: 16 August 2013 Accepted: 7 April 2014

Published: 28 April 2014

\section{References}

1. SEER Cancer Statistics Review (CSR). 1975-20011. http://seer.cancer.gov/.

2. Brenner J, Sordillo PP, Magrill GB, Golbey RB: Malignant mesothelioma of the pleura: review of 123 patients. Cancer 1982, 49:2431-2435.

3. King JA, Tucker JA, Wong SW: Mesothelioma: a study of 22 cases. South Med J 1997, 90:199-205.

4. Hirshberg A, Shnaiderman-Shapiro A, Kaplan I, Berger R: Metastatic tumours to the oral cavity: pathogenesis and analysis of 673 cases. Oral Oncol 2008, 44:743-752.

5. Kerpel SM, Freedman PD: Metastatic mesothelioma of the oral cavity. Oral Surg Oral Med Oral Pathol 1993, 76:746-751.

6. Sproat $\mathrm{CP}$, Brown $\mathrm{AE}$, Lindley RP: Oral metastasis in malignant pleural mesothelioma. Br J Oral Maxillofac Surg 1993, 31:316-317.

7. Piattelli A, Fioroni M, Rubini C: Tongue metastasis from a malignant diffuse mesothelioma of the pleura: report of a case. J Oral Maxillofac Surg 1999, 57:861-863.

8. Garcia-Reija MF, Matilla JM, De Paz A, Sanchez-Cuellar A, Verrier A: Unusual metastasis to the mandibular alveolus of malignant pleural mesothelioma. Otolaryngol Head Neck Surg 2002, 126:435-437.

9. Cassarino DS, Xue W, Shannon KJ: Widespread cutaneous and perioral metastases of mesothelioma. J Cutan Pathol 2003, 30:582-585.

10. Zanconati F, Delconte A, Bonifacio-Gori D, Falconieri G: Metastatic pleural mesothelioma presenting with solitary involvement of the tongue: report of a new case and review of the literature. Int J Surg Pathol 2003, 11:51-55.

11. Soyuer I, Soyuer S, Canöz Ö, Coşkun S, Balkanli S: Three patients with unusual metastases. Cytopathology 2004, 15:58-62.
12. Terakado N, Shintani S, Nakashiro K, Hamakawa H: Malignant pleural mesothelioma metastasis to the mandible. Int J Oral Maxillofac Surg 2004, 33:789-800

13. Tho LM, O'Rouke NP: Unusual metastases from malignant pleural mesothelioma. Clin Oncol (R Coll Radiol) 2005, 17:293. abstract.

14. Glazer CA, Waldman EH, Ansari-Lari AM, Broussard JN, Brahmer J, Tufano RP: Pathology quiz. Arch Otolaryngol Head Neck Surg 2006, 132(1012):1014-1015.

15. Higginson DS, Brahmer J, Tufano RP, Bajaj GK: Pleural mesothelioma metastatic to the tongue. J Clin Oncol 2007, 25:2133-2135.

16. Hashitani S, Sakurai K, Takaoka K, Urade M: Metastatic malignant pleural mesothelioma of the tongue: report of a case. Brit J Oral Maxillofac Surg 2009, 47:247.

17. Kirke D, Horwood K, Wallwork B: Floor of mouth and tongue metastasis from malignant pleural mesothelioma. ANZ J Surg 2010, 80:556-558.

18. Murray LJ, Higham J, Suvarna SK, Craig GT, Bridgewater CH, Fisher PM, Thornhill MH: Oral presentation of malignant mesothelioma. Oral Surg Oral Med Oral Pathol Oral Radiol Endod 2011, 111:e21-e26.

19. Sinon SH, Rich AM, Hussaini HM, Yoon HS, Firth NA, Seymour GJ: Metastases to the oral region from pleural mesothelioma: clinicopathologic review. Head Neck 2013, 35(4):599-604.

20. Cavanna L, Lazzaro A, Vallisa D, Civardi G, Artioli F: Role of image-guided fine-needle aspiration biopsy in the management of patients with splenic metastasis. World J Surg Oncol 2007, 5:13.

21. Vilmann P, Saftoiu A: Endoscopic ultrasound-guided fine needle aspiration biopsy: equipment and technique. J Gastroenterol Hepatol 2006, 21:1646-1655.

22. Whitaker D: The cytology of malignant mesothelioma. Cytopathology 2000, 11(3):139-151.

23. Sheaff M: Should cytology be an acceptable means of diagnosing malignant mesothelioma? Cytopathology 2011, 22(1):3-4

24. Husain AN, Colby T, Ordomnez N, Krausz T, Attanoos R, Beasley MB, Borczuk AC, Butnor K, Cagle PT, Chirieac LR, Churg A, Dacic S, Fraire A, Galateau-Salle F, Gibbs A, Gown A, Hammar S, Litzky L, Marchevsky AM, Nicholson AG, Roggli V, Travis WD, Wick M, International Mesothelioma Interest Group: Guidelines for pathologic diagnosis of malignant mesothelioma. 2012 update of the consensus statement from the International Mesothelioma Interest Group. Arch Pathol Lab Med 2013, 137(5):647-67.

25. Au AY, Hackl T, Yeager TR, Cohen SB, Pass HI, Harris CC, Reddel RR: Telomerase activity in pleural malignant mesotheliomas. Lung Cancer 2011, 73(3):283-288.

26. Ikeda K, Tate G, Suzuki T, Kitamura T, Mitsuya T: Diagnostic usefulness of EMA, IMP3, and GLUT-1 for the immunocytochemical distinction of malignant cells from reactive mesothelial cells in effusion cytology using cytospin preparations. Diagn Cytopathol 2011, 39(6):395-401.

27. Ikeda K, Tate G, Suzuki T, Kitamura T, Mitsuya T: IMP3/L523S, a novel immunocytochemical marker that distinguishes benign and malignant cells: the expression profiles of IMP3/L523S in effusion cytology. Hum Pathol 2010, 41(5):745-750.

28. De Rienzo A, Dong L, Yeap BY, Jensen RV, Richards WG, Gordon GJ, Sugarbaker DJ, Bueno R: Fine-needle aspiration biopsies for gene expression ratio-based diagnostic and prognostic tests in malignant pleural mesothelioma. Clin Cancer Res 2011, 17:310-316.

doi:10.1186/1477-7819-12-129

Cite this article as: Ambroggi et al:: Malignant pleural mesothelioma metastatic to the submandibular salivary gland, simulating glandular hypertrophy, diagnosed by fine-needle aspiration biopsy: a case report and literature review. World Journal of Surgical Oncology 2014 12:129. 